This is the peer reviewed version of the following article: "Roqueiro, N., Fossas, E., Oliveira, A. A. M., and Puleston, P. (2015) Variable-Structure Control with Complementarity-Inputs for a Lean-Burn IC Engine of a Series Hybrid Vehicle. Asian Journal of Control, 17: 1310-1319." which has been published in final form at [doi: 10.1002/asjc.1000]. This article may be used for noncommercial purposes in accordance with Wiley Terms and Conditions for SelfArchiving." 


\title{
VARIABLE-STRUCTURE CONTROL WITH COMPLEMENTARITY-INPUTS FOR A LEAN-BURN IC ENGINE OF A SERIES HYBRID VEHICLE
}

\author{
N. ROQUEIRO ${ }^{1}$, E. FOSSAS ${ }^{2}$, A.A. MARTINS OLIVEIRA ${ }^{3}$, P. PULESTON ${ }^{4}$
}

\begin{abstract}
This paper presents a robust controller for an internal combustion (IC) engine, as the first stage of a project to develop a hybrid light urban vehicle, running on ethanol in lean burn. In particular, this work focuses on the design of a sliding mode control for an IC engine of a series hybrid power-train. The controller must allow for optimal speed regulation and high fuel efficiency. To attain the latter, a complementary operation mode is proposed for the system inputs. Simulation results are presented and discussed showing the viability and advantages of the control strategy employed.
\end{abstract}

\section{INTRODUCTION}

The control of internal combustion engines remains an active area for the application of advanced control methods [1] [2] [3] [4] [5]. Nowadays, growing interest in hybrid powertrains offers new opportunities for pollution reduction and fuel economy [6] [7] [8]. A series hybrid powertrain appears to be the most promising architecture due to its applicability to small engines and the possibility of intermittent operation. In the current research project, this concept is being explored by a multi-institutional international team focusing on a small series hybrid powertrain for a light urban vehicle [9]. The engine of the hybrid power train will run on ethanol in lean burn, using electric cold start and warm up. It will drive a synchronous electric generator, whose voltage is rectified to feed a DC bus. It is well known that a better performance and a simpler design of a controlled rectifier can be obtained when the engine speed remains close its nominal value. Therefore, the primary objectives of this work are speed control and fuel efficiency. The efficiency attained must reach at least the US-EPA greenhouse gas score (US EPA - Vehicle Environmental Scoring) of 8. Also, the overall emissions must be in compliance with the levels stipulated in California's SULEV-II (Super Ultra Low Emission Vehicle).

This paper reports the results of the first stage of the ongoing research. Specifically, it describes a sliding-mode controller with complementary-inputs designed to improve the speed regulation and fuel efficiency of a four-stroke engine with lean-burn operation. In this initial phase, the benchmark Mean Value Engine Model (MVEM) developed by Crossley and Cook [10] is used. The original model parameters are manteined in this analysis, without loss of generality. Later this will be adapted with the actual engine parameters, once the testing of the laboratory internal combustion engine has been completed. In this context, the aim of this work was to assess the suitability of the sliding mode approach to control IC engines, with fixed open throttle under lean burn conditions, acting only on the spark advance $(\theta)$ and relative air/fuel ratio $(\lambda)$.

It has been well established that adequate lean burn conditions result in higher fuel conversion efficiencies [11]. This occurs because the combustion products have a lower specific heat at the lower combustion temperature leading to an increase in the effective polytropic coefficient during

Key words and phrases. Sliding Mode Control, IC Engine, Nonlinear Models. 
expansion. This results in a higher production of work during the expansion stroke. However, the fuel conversion efficiency decreases for excessively lean mixtures, because of the increase in the pressure fluctuations from cycle to cycle and the longer combustion period. Therefore, there is a lean operation limit, for which a small cycle to cycle variation is observed and the fuel conversion efficiency reaches a maximum. Consequently, the controller should be able to robustly regulate the engine speed at the optimal nominal value, while maintaining the mixture within the lean operation limit to a feasible extent.

The paper is organized as follows. In section 2 the model of the IC engine in lean combustion operation is introduced. Section 3 presents the design of the sliding mode controller with complementary inputs. Section 4 reports the numerical results obtained through comprehensive simulations. Finally, in section 5, conclusions are drawn and the plans for future work are outlined.

\section{INTERNAL COMBUSTION ENGINE MODELLING}

Mean Value Engine Models are dynamic models that describe dynamic engine variable responses (or changes of states) as mean values rather than instantaneous crank-angle resolved values [12]. These models do not describe the variations in the state variables over the smallest engine time scales for each cylinder, but rather the average changes in state that the engine experiences as a whole. The engine benchmark MVEM developed by Crossley and Cook [10] and implemented by MathWorks ${ }^{\circledR}$ in Simulink ${ }^{\circledR}$ is then presented (the values given for the model constants are those available in MathWorks $\left.{ }^{\circledR}\right)$.

2.1. Emptying and filling gas exchange model. The emptying and filling can be modelled as the gas exchange between two large reservoirs, whose flow is controlled by the area and discharge coefficient of the connecting passage.

According to the ideal gas law, the dynamic equation for the pressure $p_{i}(\mathrm{kPa})$ of the engine intake manifold, assuming constant temperature and volume, is

$$
\dot{p}_{i}=\frac{R T_{i}}{V_{i}}\left(\dot{m}_{a t}-\dot{m}_{a p}\right)
$$

where $R(\mathrm{~kJ} / \mathrm{kg}-\mathrm{K})$ is the universal gas constant for the fuel-air mixture, $T_{i}(\mathrm{~K})$ is the gas manifold temperature, which is assumed to be isothermal and constant, and $V_{i}\left(\mathrm{~m}^{3}\right)$ is the manifold volume, assumed to be constant. $\dot{m}_{a t}(\mathrm{~kg} / \mathrm{s})$ and $\dot{m}_{a p}(\mathrm{~kg} / \mathrm{s})$ are the mass flow rates of the air crossing the throttle valve and the mass flow rate of the mixture entering the cylinders, respectively.

The latter is given by

$$
\begin{aligned}
\dot{m}_{a p}= & -0.366+0.08979 n p_{i} \\
& -0.0337 n p_{i}^{2}+0.0001 n^{2} p_{i}
\end{aligned}
$$

where $n(\mathrm{rad} / \mathrm{s})$ is the crankshaft rotation speed.

The former is modelled as the product of two functions $f$ and $g$ :

$$
\dot{m}_{a t}=f(\alpha) g\left(p_{i}\right)
$$

where

$$
\begin{aligned}
f(\alpha)= & 2.821-0.05231 \alpha \\
& +0.10299 \alpha^{2}-0.00063 \alpha^{3}
\end{aligned}
$$


and

$$
g\left(p_{i}\right)=\frac{2}{p_{a}} \sqrt{p_{i} p_{a}-p_{i}^{2}}
$$

where $\alpha$ is the throttle plate angle and $p_{a}(101.3 \mathrm{kPa})$ is the atmospheric pressure. In this work $\alpha$ is assumed to be constant and equal to $\frac{\pi}{2}$ ( $\mathrm{rad}$ ). Thus this topology eliminates the throttle as an actuator, allowing a reduction in the cost and complexity of the control system.

2.2. Crankshaft rotation speed model. The dynamic equation for the crankshaft rotation speed, $n$, results from a balance between the load torque and the torque generated by the engine:

$$
\dot{n}=\frac{1}{I}\left(T_{e}-T_{L}\right)
$$

where $I\left(\mathrm{~kg}-\mathrm{m}^{2}\right)$ is the crankshaft load inertia, $T_{e}(\mathrm{~N}-\mathrm{m})$ is the engine torque generated and $T_{L}(\mathrm{~N}-\mathrm{m})$ is the load torque. $T_{L}$ is assumed to be as a measurable time-dependent variable with a known bound.

The torque generated by the IC engine is represented by a polynomial fit of measured data for different engine operating conditions. The equation for the engine torque is:

$$
\begin{gathered}
T_{e}=-181.3+379.36 m_{a p}+21.91\left(\frac{A}{F}\right)-0.85\left(\frac{A}{F}\right)^{2} \\
+0.26 \theta-0.0028 \theta^{2}+0.027 n-0.000107 n^{2} \\
+0.00048 n \theta+2.55 \theta m_{a p}-0.05 \theta^{2} m_{a p}
\end{gathered}
$$

where $\left(\frac{A}{F}\right)$ (dimensionless) is the air - fuel mass ratio, $\theta(\mathrm{deg})$ is the spark advance and $m_{a p}(\mathrm{~g} / \mathrm{s})$ is the mass of the gas loaded into the cylinder during the intake stroke, which takes place in the first $\pi$ radians of the crankshaft rotation of the four-stroke cycle. Thus, in the model, $m_{a p}$ was obtained by integrating the air mass flow from the manifold and resetting the integrator at the end of each intake stroke. This can be closely approximated as follows:

$$
m_{a p}=\frac{\dot{m}_{a p} \pi}{n}
$$

On the other hand, the air-fuel ratio can be computed as follows:

$$
\left(\frac{A}{F}\right)=\frac{\dot{m}_{a p}}{\dot{m}_{f}}
$$

where $\dot{m}_{f}(\mathrm{~kg} / \mathrm{s})$ is the mass flow rate of the fuel flowing into the cylinders, injected by the actuators also in the first $\pi$ radians of the crankshaft rotation.

Finally, the air-fuel ratio can be directly related to the relative air-fuel ratio $\lambda$ through a constant:

$$
\lambda=\frac{\left(\frac{A}{F}\right)}{a_{s}}
$$

where the constant $a_{s}$ is the stoichiometric air-fuel mass ratio, herein assumed to be 14.6. Note that $\lambda=1.0$ at stoichiometry, $\lambda<1.0$ for rich fuel mixtures and $\lambda>1.0$ for lean fuel mixtures. 
2.3. Fuel conversion efficiency. To conclude this section, it is important to define the fuel conversion efficiency $\eta_{f}$. Considering the lowest heating value of the fuel to be $42,000 \mathrm{~kJ} / \mathrm{kg}$, this is given by

$$
\eta_{f}=\frac{1}{B S F C 42000}=\frac{T_{e} n}{\dot{m}_{f} 42000}
$$

where BSFC stands for Brake Specific Fuel Consumption.

The fuel conversion efficiency is not used for control purposes in this paper. Instead, it is considered as an engine performance indicator.

2.4. NOx formation. The nitrogen oxides (NOx) mole concentration of the exhaust gas leaving the exhaust manifold can be approximated as [12]

$$
X_{N O}(\lambda, \theta)=X_{N O, o}(1+\Delta \lambda+\Delta \theta)
$$

where $X_{N O}(\lambda, \theta)$ is a mapping developed around a fixed point $X_{N O, o}\left(\lambda_{o}, \theta_{o}\right)$, obtained for representative constant values for the air-fuel ratio $\lambda_{o}$ and spark advance $\theta_{o}$. Functions $\Delta \lambda$ and $\Delta \theta$ take into account variations with respect to $\lambda_{o}$ and $\theta_{o}$ and take the form:

$$
\begin{gathered}
\Delta \lambda=k_{\lambda, 0}+k_{\lambda, 1}\left(\lambda-\lambda_{o}\right)+k_{\lambda, 2}\left(\lambda-\lambda_{o}\right)^{2} \\
\Delta \theta=k_{\theta, 1}\left(\theta-\theta_{o}\right)+k_{\theta, 2}\left(\theta-\theta_{o}\right)^{2}+k_{\theta, 3}\left(\theta-\theta_{o}\right)^{3}
\end{gathered}
$$

where the coefficients $k_{\lambda, 0}, k_{\lambda, 1}, k_{\lambda, 2}, k_{\theta, 1}, k_{\theta, 2}$ and $k_{\theta, 3}$ are curve fitted to measurements.

TABLE 1. NOx Model Parameters

$\begin{array}{cc}X_{N O, o} & 2162 \\ k_{\lambda, 0} & 2.1 \\ k_{\lambda, 1} & 1993 \\ k_{\lambda, 2} & -46550 \\ k_{\theta, 1} & -91.1 \\ k_{\theta, 2} & 3.14 \\ k_{\theta, 3} & 0.127 \\ \lambda_{0} & 1 \\ \theta_{0} & 25\end{array}$

To obtain the NOx mass flow rate the following approximation can be used.

$$
\dot{m}_{N O x}(\lambda, \theta)=X_{N O}(t) \frac{M_{N O x}}{M_{e g}} \dot{m}_{a p}(t)
$$

where $M_{e g}$ and $M_{N O x}$ are the molar mass of the exhaust gas and the NOx gas, respectively. Since only relative amounts of NOx emission are of interest, for the ratio $\frac{M_{N O x}}{M_{e g}}$ a value of 1 can be adopted. This simplified expression yields a sufficiently well approximated trend for the NOx concentrations [12].

Note that, similarly to the conversion efficiency, in this work the NOx mass flow rate is not used for control purposes, but only as a relevant engine performance indicator. 


\section{DEVELOPMENT OF THE SM CONTROLLER WITH COMPLEMENTARITY INPUTS}

Sliding mode techniques have proved to be effective in several areas of automotive applications (e.g., [13] [14] [15] [16]), due to their inherent robust features. In particular, this approach to the control is suitable for the problem under consideration, given that the control system must be robust in relation to the intrinsic model uncertainties and external disturbances, while being able to deal with the highly nonlinear nature of the IC engine.

In summary, the system has two physical inputs, that is, the ignition spark advance $\theta$ and the relative air-fuel ratio $\lambda$, while the output is the engine speed $n$. It should be noted that the engine is running with full open throttle, so that the air mass flow rate is not controlled. With these inputs at hand, the control objectives are to maintain the engine speed at a nominal value and to consume the minimum mass of fuel that allows the former objective to be met.

3.1. Fuel consumption minimization. Implementation of complementary inputs. The first stage towards the development of the controller is to coordinate the two physical inputs, $\lambda$ and $\theta$, so that they operate as a single "complementary-inputs actuator", where one of the inputs takes control while the other remains constant, depending on the engine speed.

This particular actuator operation is proposed to fulfil the second control objective (i.e. minimum fuel consumption during speed regulation). In this regard, certain considerations regarding the IC engine operation must be taken into account. It can be established that, for the engine under study, on operating at the leanest admissible mixture (which implies the maximum relative air-fuel ratio $\left.\lambda_{\max }\right)$ the fuel consumption is reduced. Thus, whenever possible, it is preferable to maintain constant the input $\lambda=\lambda_{\max }$ and counteract the variation in the load torque by appropriately varying $\theta$. This procedure will be adequate within a certain load range, delimited by the maximum spark advance angle, $\theta_{\max }$ (note that at $\theta_{\max }$ the maximum torque engine is generated). Therefore, once $\theta_{\max }$ is reached, this input is kept constant at $\theta=\theta_{\max }$ and higher load demands must be satisfied by manipulating the other input $\lambda$.

The outcome of this analysis is that, in practice, fuel consumption can be minimized via the operating inputs $\theta$ and $\lambda$ as follows:

$$
0 \leq\left(\theta_{\max }-\theta\right) \perp\left(\lambda_{\max }-\lambda\right) \geq 0
$$

where the symbol $\perp$ stands for complementarity, i.e., when $\left(\theta_{\max }-\theta\right)$ is not zero, then $\left(\lambda_{\max }-\lambda\right)$ is equal to zero, and vice versa.

In accordance with the following algorithm:

$$
\begin{aligned}
& \text { Case }: \theta<\theta_{\text {max }} \rightarrow \text { Mode } \theta\left\{\begin{array}{l}
\theta \text { active input } \\
\lambda=\lambda_{\max }
\end{array}\right. \\
& \text { Case }: \lambda<\lambda_{\max } \rightarrow \text { Mode } \lambda\left\{\begin{array}{l}
\lambda: \text { active input } \\
\theta=\theta_{\max }
\end{array}\right. \\
& \text { Case }: \theta=\theta_{\max } \wedge \lambda=\lambda_{\max } \rightarrow \\
& \qquad\left\{\begin{array}{l}
\text { If } \dot{\lambda}>0 \rightarrow \text { Mode } \theta \\
\text { If } \dot{\theta}>0 \rightarrow \text { Mode } \lambda
\end{array}\right.
\end{aligned}
$$

the constrained domain of the complementary inputs is shown in Figure 1. 


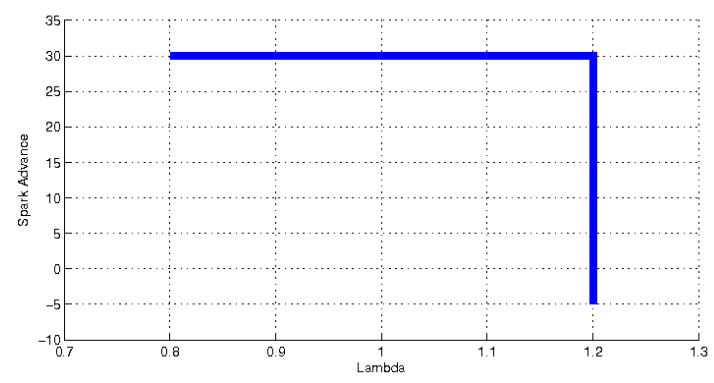

FiguRE 1. Domain of Complementary Inputs

3.2. Extended system model. In the next step, the system structure needs to be conditioned. The original IC engine model consists of two first-order differential equations, describing the speed and manifold pressure dynamics. However, in practice, it is preferable to avoid direct discontinuous signals at the inputs of the real actuators of the engine. Therefore, to smooth out the physical inputs, the original system is dynamically extended with the incorporation of integrators prior to the actual inputs (i.e., $\theta$ and $\lambda$ become states and their derivatives are the new artificial inputs). The smoothing of the control action contributes to the reduction of the undesirable chattering effect.

Then, the extended system is then fully modelled by:

$$
\begin{gathered}
\dot{n}=\frac{1}{I}\left(T_{e}-T_{L}\right) \\
\dot{p}_{i}=\frac{R T_{i}}{V_{i}}\left(\dot{m}_{a t}-\dot{m}_{a p}\right) \\
\dot{\theta}=u_{1} \\
\dot{\lambda}=u_{2}
\end{gathered}
$$

Considering the complementary operation mode described in the previous subsection, the fourthorder system can now be reduced to two alternating third-order dynamic systems:

$$
\begin{aligned}
& \text { In Mode } \theta \text { then : } \\
& \quad \dot{n}=\frac{1}{I}\left(\left.T_{e}\right|_{\lambda=\lambda_{\max }}-T_{L}\right)=f_{n_{\theta}}\left(p_{i}, n, \theta\right)-\frac{1}{I} T_{L} \\
& \dot{p}_{i}=\frac{R T_{i}}{V_{i}}\left(\dot{m}_{a t}-\dot{m}_{a p}\right)=f_{p}\left(n, p_{i}\right) \\
& \dot{\theta}=u_{1}
\end{aligned}
$$

In Mode $\lambda$ then:

$$
\begin{aligned}
& \dot{n}=\frac{1}{I}\left(\left.T_{e}\right|_{\theta=\theta_{\max }}-T_{L}\right)=f_{n_{\lambda}}\left(p_{i}, n, \lambda\right)-\frac{1}{I} T_{L} \\
& \dot{p}_{i}=f_{p}\left(n, p_{i}\right) \\
& \dot{\lambda}=u_{2} .
\end{aligned}
$$

provided that the state variables $\theta$ and $\lambda$ are forced to lie in the domain shown in Figure 1. 
3.3. SM control algorithm for speed regulation. The final step in the design is to address the fulfilment of the main control objective, that is the regulation of the engine speed at its nominal value. To formalize this objective whitin the framework of the SM control, a sliding variable is defined to force a first-order linear dynamics for the engine speed error:

$$
s=e+\tau \frac{d e}{d t}=\left(n-n_{o}\right)+\tau \frac{d n}{d t}
$$

where $e$ is the speed error, $n_{o}$ is the speed reference and $\tau$ is a design parameter that defines the stable linear dynamics of $n$ [17] [18]. $n_{o}$ is assumed to be constant, therefore $\frac{d e}{d t}=\frac{d n}{d t}$ in (22). Note that the relative degree of $s$ with respect to the inputs of the extended system is one.

With the physical inputs appropriately smoothened, the speed regulation objective embedded in the sliding variable and the fuel minimization objective contemplated in the implementation of the complementary inputs the following SM algorithm is proposed to robustly satisfy both control goals:

$$
\begin{aligned}
& \text { In Mode } \theta \text { then : } \\
& u_{1}=k_{1} \operatorname{sign}(s) \longrightarrow \theta=\int u_{1} d t=\int\left(k_{1} \operatorname{sign}(s)\right) d t \\
& u_{2}=0 \longrightarrow \lambda=\lambda_{\text {max }} \\
& \text { In Mode } \lambda \text { then }: \\
& u_{1}=0 \longrightarrow \theta=\theta_{\text {max }} \\
& u_{2}=k_{2} \operatorname{sign}(s) \longrightarrow \lambda=\int u_{2} d t=\int\left(k_{2} \operatorname{sign}(s)\right) d t
\end{aligned}
$$

Before closing this subsection it is worth noting a practical issue. During the implementation, the acceleration of the engine can provide a noisy signal if it is derived from the direct differentiation of the measured engine speed. To counteract this drawback, it could be computed through a diffeomorphism using speed and manifold pressure, two common measurements in real engines, together with the load torque value, which can be inferred from the electric power demanded by the generator. Another practical option, which is more robust to certain model uncertainties than the former, is to obtain the acceleration from a reduced order observer or different SM estimation methods [19] [20]. This issue is being considered in on going research and is not addressed herein.

3.4. Zero dynamics. The system (21) zero dynamics, named Ideal Sliding Dynamics (ISD) in the SM control framework, is the dynamics in $\mathbb{R}^{2}$ defined by $s=0$ and the full dynamics constrained to this manifold. The sliding surface is, by definition an ordinary differential equation. Thus, since the ISD is of dimension 2, we may select the pressure dynamics as the second equation. Hence, the ISD reduces to

$$
\begin{aligned}
\dot{n} & =\frac{1}{\tau}\left(n-n_{o}\right) \\
\dot{p}_{i} & =f_{p}\left(n, p_{i}\right) .
\end{aligned}
$$

Note that the $n$-dynamics is decoupled; it yields $n(t)=e^{-\frac{t}{\tau}} \cdot\left(n(0)-n_{o}\right)+n_{o}$. Hence, after some time $n=n_{o}$ can be assumed and the pressure dynamics results in

$$
\dot{p}_{i}=f_{p}\left(n_{o}, p_{i}\right) \text {. }
$$

Its stability can then be straightforwardly determined from the inspection of the plot of $\dot{p}_{i}=$ $f_{p}\left(n_{o}, p_{i}\right)$ for $p_{i} \in[0,1]$ (see Figure 2). Note that $f_{p}\left(n_{o}, p_{i}\right)$ cancels at a single point $p_{i}^{\star}$ within the interval $[0,1]$, being positive for $p_{i} \in\left[0, p_{i}^{\star}\right)$ and negative for $p_{i} \in\left(p_{i}^{\star}, 1\right]$. Hence, $p_{i}^{\star}$ is asymptotically 
stable and its basin of attraction is the whole interval $[0,1]$, amply covering the operation range of $p_{i}$.

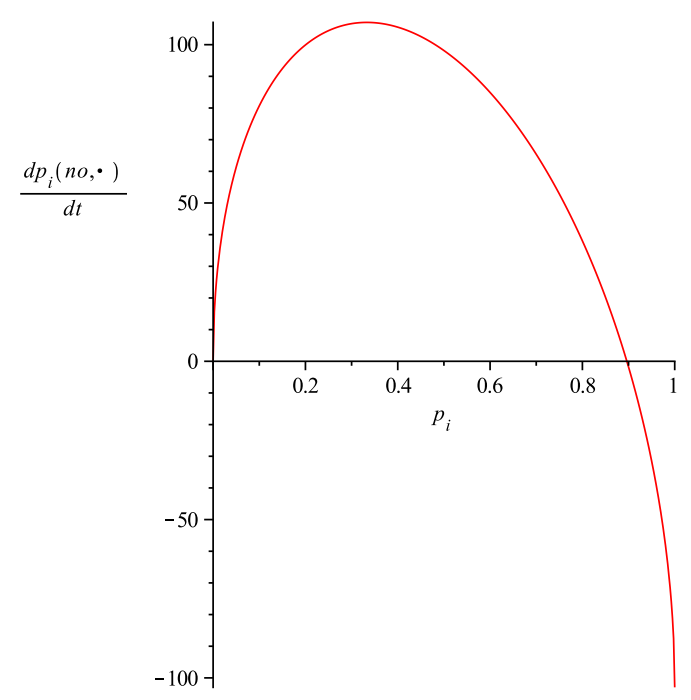

Figure 2. Graph of $f_{p}\left(n_{o}, p_{i}\right)$ for $p_{i} \in[0,1]$

3.5. Design of controller gains. Sliding Mode basin of attraction. The proposed procedure for the design discontinuous control gains of the controller is presented in this subsection. Two main features are considered for the calculation of $k_{1}$ and $k_{2}$, firstly, to provide the controller with sufficient control authority to deal with a wide range of load torques, namely:

$$
T_{L_{\min }}=5 \leq T_{L} \leq T_{L_{\max }}=54 \text {. }
$$

and secondly to guarantee a secure basin of attraction. Taking into account the operation characteristics of the IC engine, the following values were set:

$$
s_{\min }=-500 \leq s \leq s_{\max }=500 .
$$

To start the design procedure, the expression of the continuous control action which maintains $s$ invariant at an arbitrary constant value $K$ (hereinafter referred to as $u_{e q_{K}}$ ) is obtained from $\dot{s}=0$ evaluated at $s=K$ :

$$
u_{e q_{K}}=\left.u\right|_{\substack{\dot{s}=0 \\ s=K}} .
$$

It should be recalled that in Mode $\theta$ or Mode $\lambda$, the system is dependent on four variables: three states $\left(\left[\begin{array}{lll}n & p_{i} & \theta\end{array}\right]^{T}\right.$ or $\left[\begin{array}{lll}n & p_{i} \lambda\end{array}\right]^{T}$, respectively) and the external load torque $T_{L}$. Therefore, taking advantage of the algebraic relationship set by condition $s=K$ in (29), one variable can be eliminated and $u_{e q_{K}}$ can be expressed as a reduced function of three variables. In this work, the state variables were preferred, so $T_{L}$ was eliminated, resulting in:

$$
\begin{aligned}
& \text { Mode } \theta \rightarrow u_{1 e q_{K}}\left(n, p_{i}, \theta\right), \\
& \text { Mode } \lambda \rightarrow u_{2 e q_{K}}\left(n, p_{i}, \lambda\right) .
\end{aligned}
$$


In addition, for the design, a known upper bound for the time derivative of $T_{L}$ equal to $20(\mathrm{Nm} / \mathrm{s})$ was assumed.

The value for $u_{e q_{K}}$ in (30) is then computed for the whole state range of operation, considering different values for $\mathrm{K}$, viz.: the external limits $\left(K=s_{\min }\right.$ and $\left.K=s_{\max }\right)$ and additional representative internal values $(K=-200,0,200)$. The former will provide upper and lower bounds for $u_{e q_{K}}$ which, in turn, are used as the discontinuous control gains to ensure the attraction inside the pre-selected basin.

The operation range of the system under study is:

$$
\begin{aligned}
& n_{\min }=1294 \leq n \leq n_{\max }=1354 \\
& p_{i_{\min }}=0.8953 \leq p_{i} \leq p_{i_{\max }}=0.8973 \\
& \lambda_{\min }=0.9 \leq \lambda \leq \lambda_{\max }=1.2 \\
& \theta_{\min }=-5 \leq \theta<\theta_{\max }=30
\end{aligned}
$$

Figures (3) and (4) illustrate $u_{1 e q_{K}}$ and $u_{2 e q_{K}}$, respectively, parametrized in terms of $K=-500,-200,0,200,500$ for a single pressure value, in this case the central value $p_{i}=0.8963$.

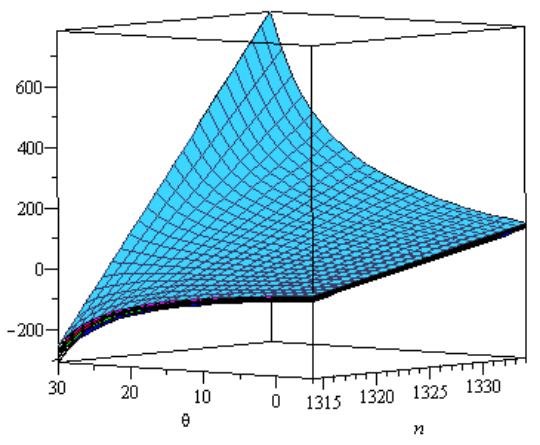

Figure 3. $u_{1 e q_{K}}$ parametrized in terms of $K=-500,-200,0,200,500$ for a constant $p_{i}=0.8963$.

In practice, increasing or decreasing the pressure value results in vertical translations of the $u_{1 e q_{K}}$ and $u_{2 e q_{K}}$ graphs. Hence, computing $u_{1 e q_{K}}$ and $u_{2 e q_{K}}$ for the extreme pressure values, $p_{i_{\min }}=0.8953$ and $p_{i_{\max }}=0.8973$, give the sought-after bounds, namely:

$$
\begin{aligned}
& -800 \leq u_{1 e q_{K}} \leq 800 \\
& -60 \leq u_{2 e q_{K}} \leq 60
\end{aligned}
$$

Consequently, designing $k_{1}=800$ and $k_{2}=60$ guarantees the aforementioned basin of attraction, as well as robustness in relation to the load torque disturbances in (27).

Note that for the design of the gains a $20 \mathrm{Nm} / \mathrm{s}$ bound for the load torque derivative was assumed. Therefore, in cases with abrupt time derivatives such as the exacting torque step series presented in the Simulation Results section, the controller cannot ensure insensitivity and the system transiently escapes from the sliding manifold. Nonetheless, it remains inside the attraction basin and hence it robustly returns to $s=0$. 


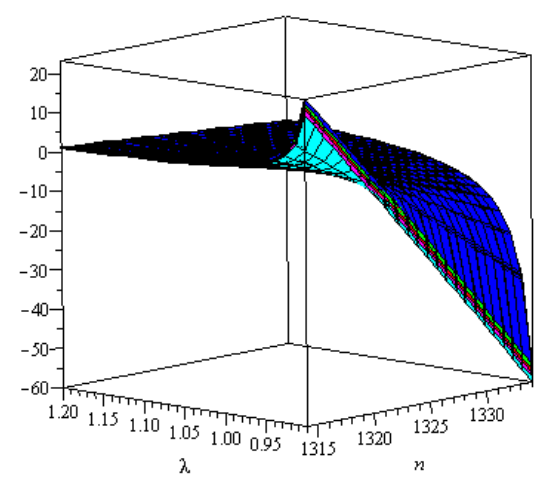

FIGURE 4. $u_{2 e q_{K}}$ parametrized in terms of $K=-500,-200,0,200,500$ for a constant $p_{i}=0.8963$.

\section{SIMULATION RESULTS}

To determine the feasibility of the proposed SM approach to control a lean-burn IC engine, the performance and robustness of the SM control strategy was assessed through intensive simulation tests. Given that real actuators can saturate, anti wind-up integrators were used in the simulations, and these will be later implemented in the actual engine. In this section, some representative results are presented.

For these tests, the IC engine is subjected to an exacting series of load demand steps (see Figure 5). In fact, in actual applications the load regime is not so abrupt, but this series was selected to present the controller with an exigent trial.

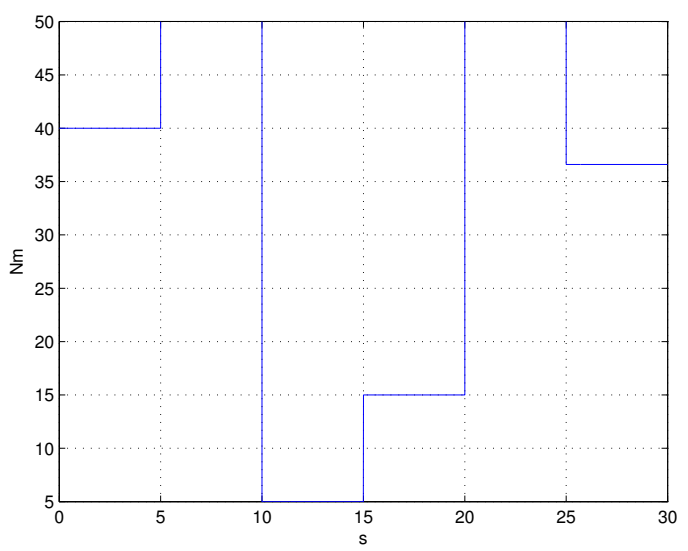

Figure 5. Load torque (N-m). 
In addition to observing the controller behaviour it is of interest to establish comparisons, and hence the proposed SM controller with complementary inputs is contrasted with a stoichiometric SM controller. In the latter, the injector is commanded to maintain the air-fuel mass at a stoichiometric ratio of $a_{s}=14.6$ (which implies constant input $\lambda=1$ ), while the input $\theta$ is controlled by an integrated discontinuous control action $\left(\theta=\int(k \operatorname{sign}(s)) d t\right)$. The speed error obtained with the two controllers under undisturbed conditions are shown in Figure 6 (in blue and red). The reference value for the engine angular speed is set at $n_{0}=1324 \mathrm{rad} / \mathrm{s}$. Note that the values for the error amplitude and the settling times are comparable for both control set-ups.

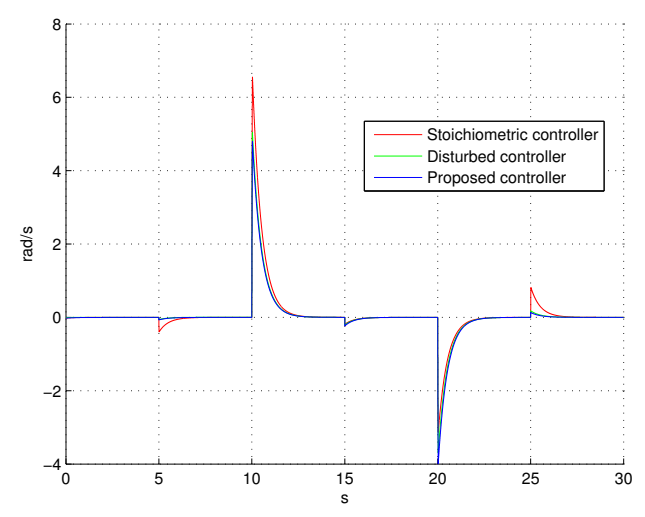

FiguRE 6. Engine speed error (rad/s).

In order to investigate the proposed controller performance in the presence of lumped disturbances, in a subsequent test a $10 \%$ error was added to the nominal engine torque. This error term is intended to take into account the effects of model parameter uncertainties and/or unmeasurable perturbations, assuming them to be unknown but bounded. The results obtained satisfactorily confirm the robustness of the controller in relation to disturbances that can be grouped in this form.

Figures 7 and 8 show the time evolution of the spark advance and $\lambda$ for the stoichiometric SM controller (under nominal conditions of operation) and the proposed SM controller (nominal and disturbed). The complementarity of the proposed inputs can be clearly observed in these figures (see blue and green lines, which correspond to the designed controller).

The success of the proposed complementary inputs strategy in relation to attaining a reduction in fuel consumption can be evaluated through the fuel conversion efficiency, defined as a performance indicator in (11). It can be verified in Figure 9 that the efficiency of the implementation of the SM complementary inputs is better than that of the engine controlled to operate with a stoichiometric mixture.

In Figure 10 the trend of normalized NOx pollutant production is shown. Although the production of pollutants was not an explicit objective of this paper, it is interesting to verify that the proposed controller can also reduce the production of NOx. 


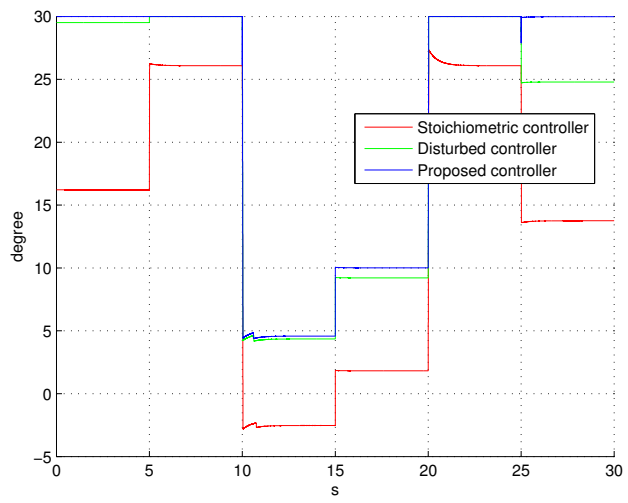

Figure 7. Spark advance (deg).

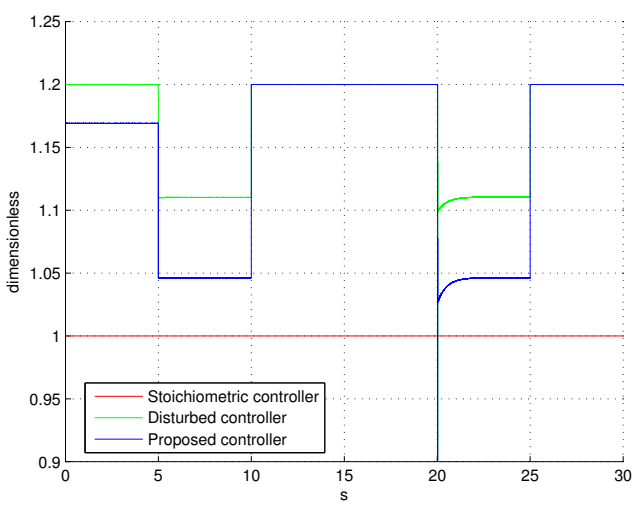

FiguRE 8. Lambda.

\section{Conclusions And Future WORK}

The results presented in this paper correspond to the first stage of a broader research project aimed at developing a control system for the actual IC engine of a novel hybrid vehicle. The purpose of this initial stage was to design a robust controller for an IC engine based on Sliding Mode techniques and the implementation of complementary inputs able to deal with lean burn operation. To assess the feasibility of this approach, rather than the actual parameters of the engine under construction, a well-tested simulation benchmark model was used.

For the development of the controller the system was expanded with integrators at the inputs, to provide a smooth control action for the actuators. The designed SM controller successfully fulfilled two simultaneous control objectives: robust regulation of the engine speed at its nominal value and a reduction in the fuel consumption. The former was attained by defining the sliding surface in 


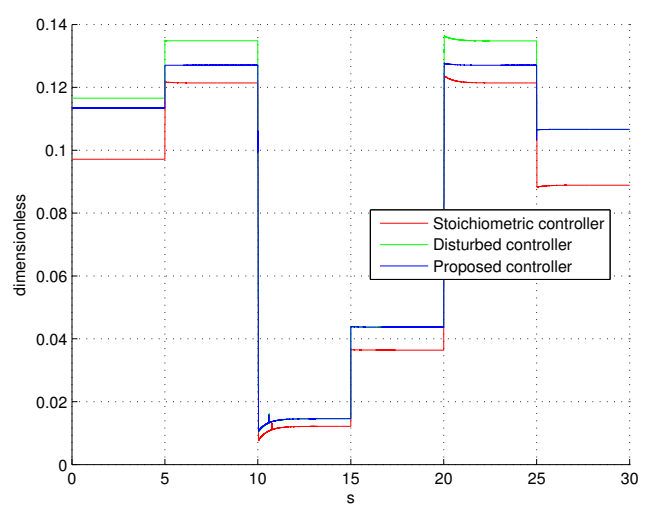

Figure 9. Fuel conversion efficiency.

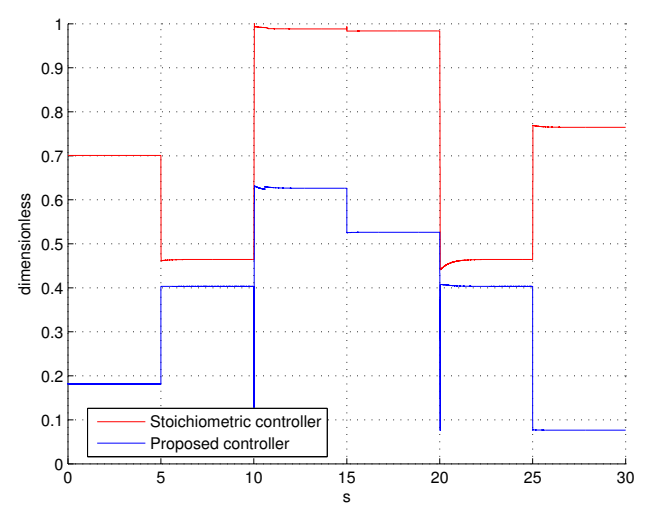

FiguRE 10. Normalized NOx production

terms of the speed error. The latter was fulfilled through the implementation of complementary inputs.

Extensive simulation results show that the SM controller is able to deal with a lean-burn engine with wide open throttle by acting only on the air-fuel ratio and spark advance. Moreover, the proposed system topology eliminates an actuator (the throttle) and hence the cost and complexity of the control system are substantially reduced. Finally, it is of particular relevance to highlight that the fuel efficiency attained with the proposed control strategy is better than that obtained with the IC engine operating at a fixed stoichiometric air-fuel ratio.

Encouraged by these promising results, future work will envolve the development of an engine model of the actual hybrid power train as well as the design, implementation and experimental testing of the SM based control system in the real engine and further studies on its robustness under exacting conditions. 


\section{REFERENCES}

[1] Cook JA, Sun J, Buckl JH, Kolmanovsky IV, Peng H, Grizzle JW. Automotive powertrain control - a survey. Asian Journal of Control 2006; 8:237 - 260.

[2] He B, Ouyang M, Li J. Reduced order robust gain-scheduling control of the diesel apu for series hybrid vehicles. Asian Journal of Control 2006; 8:227 - 236.

[3] Xie L, Ogai H, , Inoue Y. Modeling and solving an engine intake manifold with turbo charger for predictive control. Asian Journal of Control 2006; 8:210 -218.

[4] Alt B, Blath J, Svaricek F, Schultalbers M. Control of idle engine speed and torque reserve with higher order sliding modes. Control Applications, (CCA) Intelligent Control, (ISIC), 2009 IEE, 2009.

[5] Puleston PF, Spurgeon SK, Monsees G. Automotive engine speed control: A robust nonlinear control framework. IEE Proceedings-Control Theory and Application 2001; 148(1):81-87.

[6] J B Vance SJ B C Kaul, Drallmeier JA. Output feedback controller for operation of spark ignition engines at lean conditions using neural networks. IEEE Transacion on Control Systems Technology 2008; 16-2:214-228.

[7] Jing Hu FL Bing Xiao, Hu J. The lean burn control for lpg engine using torque estimation. IEEE International Conference on Control and Automation, 2007.

[8] Zhang F, Grigoriadist K, Franchek M, Makki I. Linear parameter-varying lean burn air-fuel ratio control. Decision and Control, 2005 and 2005 European Control Conference. CDC-ECC '05. 44th IEEE Conference on, 2005.

[9] Roqueiro N. Propulsor hibrido para veiculo urbano leve. CNPq project number 402376/2009-9 MCT/CNPq no 18/2009 - P\&D\&I em Transportes.

[10] Crossley P, Cook J. A nonlinear engine model for drivetrain system development. IEE International Conference 'Control 91', 1991.

[11] Heywood JB. Internal Combustion Engine Fundamentals. McGraw-Hill, 1988.

[12] Guzzella L, Onder C. Introduction to Modeling and Control of Internal Combustion Engine Systems. Springer, 2004.

[13] Wang S, Yu D. An application of second-order sliding mode control for ic engine fuel injection. Electrical and Computer Engineering, 2006. CCECE '06. Canadian Conference on, 2006.

[14] Zhang Y, Kurihara N. A study of discrete-time sliding mode control for si engine idle speed control. Industrial Technology (ICIT), 2011 IEEE International Conference on, 2011.

[15] Wang H, Man Z, Kong H, Shen W. Terminal sliding mode control for steer-by-wire system in electric vehicles. Proceedings of ICIEA 2012 2012; :919-924.

[16] Wang H, Kong H, Man Z, Tuan D, Cao Z, Shen W. Sliding mode control for a steer-by-wire system with ac mmotor in road vehicles. IEEE Transaction on Industrial Electronics 2014; 61(3):1596-1611.

[17] Utkin V. Sliding Mode and Their Applications in Variable Structure Systems. MIR, Moscow, 1978.

[18] Slotine J, Li W. Applied Nonlinear Control. Prentice-Hall, 1991.

[19] Edwards C, Spurgeon SK, Tan CP, Patel N. Sliding-Mode Observers. In Mathematical Methods for Robust and Nonlinear Control. Lecture Notes in Control and Information Sciences Vol.367, Springer, 2007.

[20] Bartolini G, Fridman L, Pisano A, Usai E ( (eds.)). Modern Sliding Mode Control Theory. New Perspectives and Applications. Lecture Notes in Control and Information Sciences Vol.375, Springer-Verlag, 2008.

\section{Biographies}

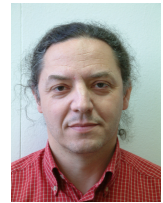

Enric Fossas Colet, Full Professor in Control Systems and Automation at Universitat Politècnica de Catalunã (UPC), graduated in Mathematics in 1981 and received his Ph.D. degree in Mathematics in 1986, both from Universitat de Barcelona. In 1986 he joined the Department of Applied Mathematics at the UPC, where he served as Head of Department from 1993 to 1999. In 1999 he moved to the Department of Automatic Control and Computer Engineering (UPC) and to the Institute of Industrial and Control Engineering, being the director of the Institute from July, 2003 to July, 2009. Since 2013 he is the Rector of the UPC. His research interests include non-linear control (theory and applications), particularly Variable Structure and Hybrid Systems, with application to switching converters. He is author/co-author of more than 100 scientific papers presented at conferences or published in specialized journals and of five books: Variable Structure Systems: from principles 
to implementation, Advances in Variable Structure and Sliding Mode Control, Sliding Modes after the First Decade of the 21st Century, Dynamics and Control of Switched Electronic Systems and Port-Controlled Hamiltonian Systems.

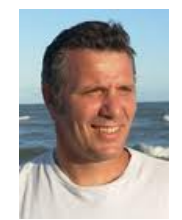

Prof. Paul Puleston received his Electronic Engineering degree (with first class Hons.) and his Ph.D. degree from the Universidad Nacional de La Plata (UNLP), Argentina, in 1988 and 1997, respectively. He is currently Full Professor at the Department of Electrical Engineering, FI-UNLP, Vice Director of the LEICI and Researcher of the Consejo Nacional de Investigaciones Cientficas y Tecnicas (CONICET) at LEICI, Argentina. His main research field is automatic control systems, theory and applications, including alternative energy systems.

Prof. Amir Antnio Martins de Oliveira Junior graduated in Mechanical Engineering

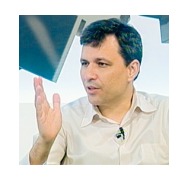
in the Department of Mechanical Engineering at UFSC (1989), received his Masters in Mechanical Engineering from the Graduate Program in Mechanical Engineering at UFSC (1993) and received his Ph.D. from the Mechanical Engineering Department of Mechanical Engineering and Applied Mechanics University of Michigan at Ann Arbor, MI (1998). He is currently a Professor at the Department of Mechanical Engineering, Federal University of Santa Catarina and a member of the Scientific Committee of the National Combustion. He has experience in Mechanical Engineering with emphasis on Transport Phenomena and Combustion, researching the following themes: heat and mass transfer, fluid mechanics, combustion kinetics, porous media, and electrochemical membranes, fuel cells and internal combustion engines.

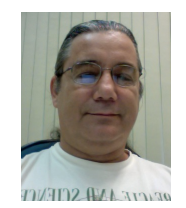

Prof. Nestor Roqueiro graduated in Electronics Engineering - Universidad Nacional de San Juan (1985), received his Masters in Electrical Engineering from the Alberto Luiz Coimbra Institute for Graduate Studies and Research in Engineering (1989) and receives his Ph.D. in Chemical Engineering from the Alberto Luiz Coimbra Institute for Graduate Studies and Research in Engineering (1995). He is currently a Professor at the Federal University of Santa Catarina and is Director of the Laboratory for Innovation. His current research interests include hybrid powertrains for urban vehicles and the dynamics of tilting vehicles.

Acknowledgment: Nestor Roqueiro acknowledges the support of CNPq (Brazil) research project 402376/2009-9. Enric Fossas acknowledges the support of Spanish government research projects DPIDPI2010-15100 and DPI2008-01408. Paul Puleston was supported by UNLP, CONICET and ANPCyT (Argentina), and Marie Curie FP7-2011-IIF, ACRES (299767/911767) (EU). 